\title{
Generate Real Total Radiation Spatial Distribution of Solar Radiation Using Cloud Mask Algorithm
}

\section{Introduction}

The main goal of this paper is to illustrate the opportunities the r.sun model provides for assessing the solar potential of a selected area under the real sky conditions. The issue of using the r.sun model for generating the spatial distribution of the total solar radiation was discussed in previous works, e.g. those of Hofierk, Suri and Kryza [7, 8, 12, 15, 17, 16]. However, these works do not include the clouds' impact on the total amounts of solar radiation.

In general, the spatial distribution of solar radiation is determined by numerous elements, such as:

- terrain,

- atmosphere,

- pollutants,

- water and aerosol in the atmosphere,

- clouds and shadowing effects of the surrounding buildings.

The key problem is obtaining the incident solar radiation on a regional scale. In such a case, the major factors modifying the distributions of the radiation are the local shadowing effects of the terrain (e.g. slopes and aspects). Apart from that, the local shadowing effects of the terrain are no less important. Another crucial feature that should be taken into account during the solar analysis is the cloud cover. As the clouds constitute a barrier for the radiation of the sun, the solar radiation models should include the cloud cover. So far, this problem has been examined in numerous studies, and some authors Miklánek, Suri, Hofierka [6, 13, 17, 16] used data from the local ground stations to determine the range of the clouds. However, such data is reliable exclusively for a region surrounding the station. Therefore, satellite data is more suitable to reliably assess cloudiness. Such data includes the image of the cloud cover for the selected area and, most importantly, it shows the cloud cover over all the terrain.

\footnotetext{
* University of Lower Silesia, Department of Technical Science, Wrocław, Poland
} 


\section{Input Data}

Input data for spatial solar radiation distribution consists from:

a) the digital elevation model of the terrain for the selected area,

b) the maps of the slopes and aspects,

c) atmospheric turbidity data (in this case the Linke Turbidity Factor - LTF),

d) satellite data from LANDSAT 7 programme.

Ad a) The digital elevation terrain model is in the grid based format of spatial data. The terrain model used in this work has the resolution of 50 meters and covers the area of Lower Silesia. The final result includes a smaller area due to fitting the satellite scene and Lower Silesia province borders.

Ad b) Those maps were created using the r.slope.aspect command in GRASS. The slope and aspect values are calculated based on the DEM raster maps. Examples of slope and aspect raster maps are presented below. Slope and aspect are given in degrees by default. In the case of aspect maps, the categories represent the degree number from the eastern direction, increasing counter clockwise: $90^{\circ}$ is North, $180^{\circ}$ is West, $270^{\circ}$ is South, $360^{\circ}$ is East. The aspect value $0^{\circ}$ is used to indicate an undefined aspect in the case of flat areas with a slope of 0 . Slope and aspect raster maps will be used as input data in the analysis of the spatial distribution of solar radiation, using the r.sun model.

Ad c) This parameter describes the value of solar radiation attenuation by the atmosphere. The attenuation of solar radiation is a result of absorption and dispersion of the solar radiation by the atmosphere. It can be decomposed into two components: the weakening caused by the gas constant (ideally present in the atmosphere), and caused by the water vapour and aerosols. The extinction coefficient includes both these components. Because the extinction coefficient for the ideal atmosphere is known, we can designate the ratio of extinction coefficients for the real and ideal atmosphere. This ratio is called the atmospheric turbidity factor.

The average value of turbidity factor in the temperate latitudes in lowland areas shall be 3, in big cities [1], where the air is particularly polluted it exceeds 4 , in mountainous areas is in the range of 2 to 3 . In winter, the value of the turbidity factor is the lowest. The highest value is in summer; this is a result of the annual course of air humidity and dust changes [1].

As for the atmospheric turbidity data, in this study it was gathered using the LTF. The value of this factor depends on the solar elevation angle, the water vapour and the aerosols content in the atmosphere. In this study the LTF value is constant within each month (Tab. 1). Table 1 presents the average value of the LTF for each month and for different types of land use.

Ad d) Data from LANDSAT 7 programme archives was used to generate the cloud mask, which is one of the cloud cover estimation methods in real solar radiation calculations. The cloud cover was based on the satellite images obtained from 
the National Aeronautics and Space Administration (NASA) web page [14]. Satellite image was presented cloud cover of 18 April 2011. On the NASA site satellite data from several programmes and for many geographical locations is available [14]. Landsat archives are free and available on the LANDSAT programme web page. To collect the data from the Landsat archive user has to register on the EarthExplorer website. After that the user can browse and download the data.

Table 1. The average monthly values of the Linke turbidity coefficient for mild climate

\begin{tabular}{|c|c|c|c|c|c|c|c|c|c|c|c|c|c|}
\hline \multirow{2}{*}{ Type of land use } & \multicolumn{12}{|c|}{ Month } & \multirow{2}{*}{ Year } \\
\hline & I & II & III & IV & V & VI & VII & VIII & IX & $x$ & XI & XII & \\
\hline Mountains & 1.50 & 1.60 & 1.80 & 1.90 & 2.00 & 2.30 & 2.30 & 2.30 & 2.10 & 1.80 & 1.62 & 1.50 & 1.90 \\
\hline Rural Area & 2.10 & 2.20 & 2.50 & 2.90 & 3.20 & 3.40 & 3.50 & 3.30 & 2.90 & 2.60 & 2.30 & 2.20 & 2.75 \\
\hline City & 3.10 & 3.20 & 3.50 & 4.00 & 4.20 & 4.30 & 4.40 & 4.30 & 4.00 & 3.60 & 3.30 & 3.10 & 3.75 \\
\hline Industrial Area & 4.10 & 4.30 & 4.70 & 5.30 & 5.50 & 5.70 & 5.80 & 5.70 & 5.30 & 4.90 & 4.50 & 4.20 & 5.00 \\
\hline
\end{tabular}

Source: [8]

\section{Cloud Mask}

For generating a cloud mask from a Landsat image, two algorithms were used: i.landsat.toar and i.landsat.acca [3-5]. The i.landsat.toar is an algorithm used to calculate the top-of-atmosphere radiance or reflectance and the temperature for the Landsat MSS/TM/ETM+ sensors. This algorithm is used to transform the digital images of Landsat to the top-of-atmosphere radiance or the top-of-atmosphere reflectance and temperature which are presented as raster maps of this value. Command syntax of i.landsat.toar is available in GRASS manual [4, 5].

Now all the data necessary to create the cloud mask is complete. Raster maps which present cloud cover will be generated using the i.landsat.acca command. i.landsat.acca implements the Automated Cloud Cover Assessment (ACCA) algorithm $[4,5,9,10]$, which uses threshold values in Landsat bands Nos 2, 3, 4, 5 and 6, based on the value of frequency response for the clouds in each band.

ACCA uses five of the eight ETM+ spectral bands:

- Band-2 (B2): 0.53-0.61 $\mu \mathrm{m}$, green, $30 \mathrm{~m}$ resolution,

- Band-3 (B3): 0.63-0.69 $\mu \mathrm{m}$, red, $30 \mathrm{~m}$ resolution,

- Band-4 (B4): 0.78-0.90 $\mu \mathrm{m}$, near infrared, $30 \mathrm{~m}$ resolution,

- Band-5 (B5): 1.55-1.75 $\mu \mathrm{m}$, shortwave infrared, $30 \mathrm{~m}$ resolution,

- Band-6 (B6): 10.4-12.5 $\mu \mathrm{m}$, thermal infrared, $60 \mathrm{~m}$ resolution. 
ACCA operates on the premise that clouds are colder than the land surface they cover. The algorithm was designed for Landsat 7 ETM+ but because reflectance is used, it is also useful for Landsat 4 and 5 TM.

The i.landsat.acca is very simple and fast to use. The bands which were created by using the i.landsat.toar command are all the necessary inputdata. The user can use [-f] flag to fill all small holes in the clouds. The use of the i.landsat.acca algorithm results in generating raster maps. All the pixels in these maps have one of the two values cold clouds - red color on the map or warm clouds - yellow color. Finally, to create the cloud mask which can be used in the solar analyses, the r.mapcalc command has to be used. r.mapcalc creates the mask of clouds called MASK. Now all pixels have value 0 or 1,1 - "cloud" - blue color on the map or 0 - "not-cloud" white color on the map (Fig. 1).

a)

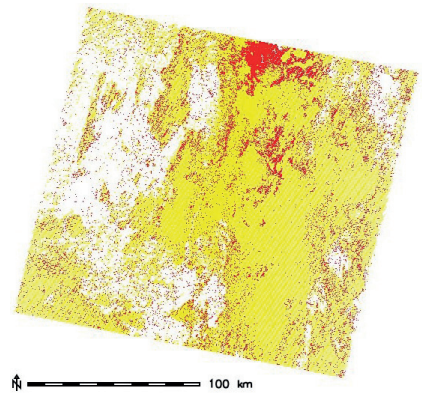

b)

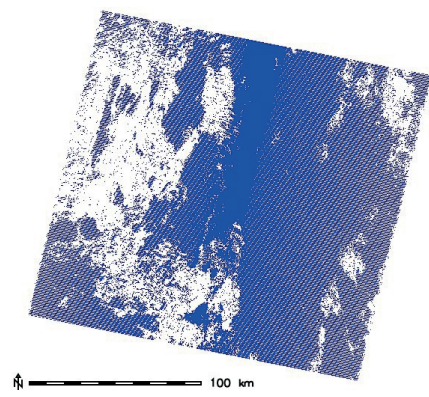

c)

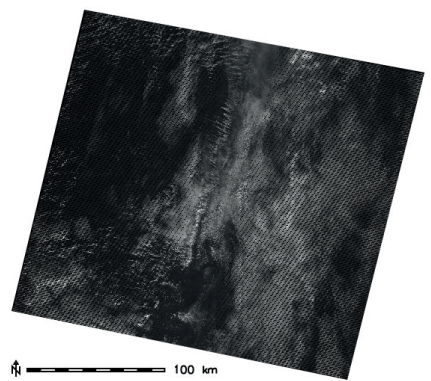

Fig. 1. Maps created using the i.landsat.acca algorithm (a), cloud mask (b) and satellite scene (c)

\section{The r.sun Model}

The r.sun is one of the GRASS commands. It is used to analyse the spatial distribution of solar radiation (direct, diffuse and reflected). It is based on the terrain model and its derivatives (slope, aspect, etc.), atmospheric parameters (LTF, water vapour) and astronomical calculations (sun azimuth and elevation for a given location on Earth, etc.). It produces raster maps for a given day, latitude, terrain and atmospheric conditions. Solar parameters (e.g. sunrise and sunset times, declination, extra-terrestrial irradiation, daylight length) are saved in the map history file. The shadowing effect of the topography is optionally incorporated [-s flag]. Because of the large set of parameters, the syntax of r.sun is complicated. However, many of the parameters are optional and many have default values.

The r.sun model is also suitable for integrating coefficient of the atmosphere turbidity, described by the LTF factor. Other elements are: albedo, latitude, raster 
map with the value of real-sky beam radiation coefficient and raster map with the value of real-sky diffuse radiation coefficient, number of the day from 1 to 365, time resolution of the analysis, declination value, and sampling distance step coefficient. The output parameters are: beam irradiation raster map, diffuse irradiation raster map, global irradiation raster map, ground reflected irradiation raster map, incidence angle raster map, insolation time raster map.

The r.sun model does not include the cloud cover in the solar analysis. That means that the results of the r.sun calculation of the solar radiation give us only the spatial distribution of the potential solar radiation. To get the spatial distribution of the real solar radiation it is necessary to apply the cloud cover parameter in the analyses. It is possible through the use of the raster maps with cloud cover parameters which were generated before (the MASK layer). Application of the MASK layer for the r.sun calculations gives the real distribution of solar radiation as a result.

\section{Results}

The use of the cloud mask, generated with the i.landsat.acca algorithm, enabled including the cloud cover element in the solar radiation distribution. The results of the analysis of the solar radiation distribution are presented in Figure 2. This map was generated using the r.sun model with the cloud mask raster map. As a consequence, this raster map presents a solar radiation distribution under the real sky conditions, i.e. with cloud cover.

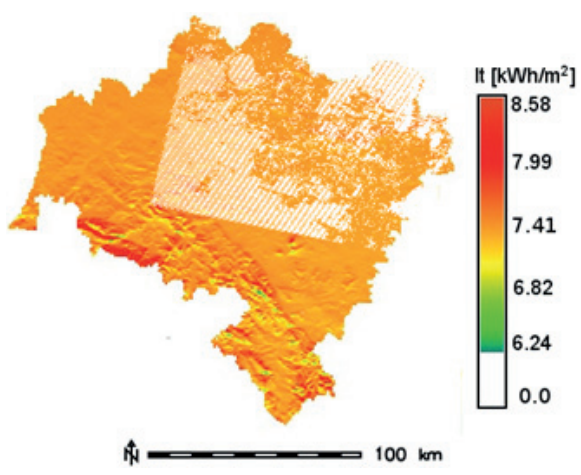

Fig. 2. Raster maps of total solar radiation for given day (18.04.2011) with use of cloud mask

The raster map of the spatial distribution of the real total solar radiation is presented in the picture below (Fig. 2). As can be seen, there are areas where the value of solar irradiation amounts to $0 \mathrm{~kW} / \mathrm{m}^{2}$ (white colour on the map). These areas were covered by clouds. In the remaining part of the area that was not covered by 
the clouds, the irradiation is over $7.0 \mathrm{kWh} / \mathrm{m}^{2}$ (orange colour on the map). I.landsat. acca is a very efficient and fast method, allowing the user to create the cloud mask. Nevertheless, the ACCA algorithm does not solve the problem of the cloud cover to the end. As can be seen in Figure 1a, the cloud mask generated by i.landsat. acca allocated all the pixels from the raster maps between two categories: cloud or not-cloud (0 or 1). The issue of clouds transparency is not resolved. Each cloud type has a different transparency, for example Stratus has different properties than Cirrus. This issue should be expanded in future studies, because in the current study all the types of clouds in the solar distribution analysis have the same transparency. This is not true.

Determination of the degree of absorption of sunlight by clouds is important to create the solar radiation spatial analysis. Using the ACCA algorithm we can only approach the real sky conditions. Another problem with the cloud mask is that the pixels with cloud are determined as non-translucent. Consequently, they constitute a $100 \%$ - barrier for the solar radiation.

\section{Discussion}

This paper present a new approach to the important problem of analysing the spatial distribution of total solar radiation under the real sky conditions using satellite data. In this study, several assumptions have been made. One of them applies to the problem of the LTF factor. First of all, it proposes to use the LTF value dependent of the land use. In previous work, the authors proposed to use the LTF value as a constant over the study area [13]. Calculating the LTF factor in this case requires the PWC (precipitable water vapour in $\mathrm{cm}$ ) and AOT (aerosol optical thickness). The value of the LTF factor is calculated according to the formula proposed by Doginaux [2]. Information about PWC is based by aerological soundings taken from the nearby station. The AOT data is available through the AERONET project database.

However, this approach does not seem to take into account the spatial variation of the LTF parameter. Therefore, in this study we propose to use the average monthly values of the Linke turbidity coefficient for a mild climate, which are dependent on the land use type. As was mentioned above, the relationship between the LTF factor and land use was described e.g. by Chromow [1]. The relation between land use and the LTF factor should not be omitted in the spatial analysis. An important issue which needs to be developed is the LTF factor value at the border between areas of different types of land use.

Another important issue is to take into account the value of cloud transparency. Admittedly, this issue was described in the previous work of Kasten and Czeplak [11]. However, it is still difficult to associate this parameter with satellite data. 


\section{Summary}

The use of the r.sun model to calculate the total solar radiation for a large area, covering the Lower Silesia region, gives good results. In the case of the r.sun model under the clear-sky conditions, they prove to be compatible with the measurement values. Therefore the r.sun model can be regarded as an efficient method of determining the spatial distribution of incoming solar radiation. However, this model tends to underestimate the solar radiation in the real-sky conditions. Therefore, the r.sun gives the most precise results for the clear, cloudless sky. In spite of this fact, it is possible to use the r.sun model to calculate the incoming solar radiation in the real-sky conditions. In this case the ACCA algorithm is helpful. Using ACCA, a cloud mask can be created. Additionally, satellite data from the Landsat program archive, which is free and easy to get from the NASA website, is indispensable in this process. Everyone can download data from Landsat to create a raster map from satellite images. In such a case the following GRASS image command is helpful: i.landsat.toar. As a consequence, the use of the cloud mask, generated by the GRASS command i.landsat.acca, enables the estimation of the incoming solar radiation in cloudy conditions. The result of using the ACCA algorithm is a raster map on which every pixel is described as cloud or not-cloud. Therefore, the cloud transparency cannot be included in the spatial distribution of the total solar radiation analysis.

The cloud cover element is very important in the spatial distribution analysis of the total solar radiation. For this reason, the issues of the cloud mask and the cloud transparency should be taken into consideration. Investigating the issue of transparency of different clouds types further should be the next step in the spatial analysis of total solar radiation in the real sky conditions.

The analyses presented above should be treated as corroborating the use geographical information systems (GIS) and satellite data to generate spatial distributions of total solar radiation under real sky conditions, and maybe also, in future, to forecast the solar resources in the selected area.

\section{References}

[1] Chromow S.P.: Meteorologia i klimatologia. PWN, Warszawa 1969

[2] Dogniaux R.: De l'infl uence de l'estimation du facteur total de trouble atmosphérique sur l'évaluation du rayonnement solaire direct par ciel clair. Institut Royal Météorologique de Belgique (IRM), Miscellanea 1984, Serie C, pp. 20.

[3] GRASS Development Team, 2011. Tutorials. [on-line:] grass.meteo.uni. wroc.pl [access: 21.04.2016].

[4] GRASS Development Team, 2011. [on-line:] http://grass.osgeo.org/grass70/ manuals/i.landsat.acca.html [access: 21.04.2016]. 
[5] GRASS Development Team, 2011. [on-line:] http:/grass.osgeo.org/grass70/ manuals/i.landsat.toar.html [access: 21.04.2016].

[6] Hofierka J., Cebecauer T.: Spatially distributed assessment of solar resources for energy applications in Slovakia. Acta Facultatis Studiorum Humanitatis et Naturae Universitatis Prešoviensis. Prírodné vedy, Folia Geographica, vol. 12, 2008, pp. 97-114.

[7] Hofierka J., Kanuk J.: Assessment of photovoltaic potential in urban areas using open-source solar radiation tools. Renewable Energy, vol. 34 (10), 2009, pp. 2206-2214.

[8] Hofierka J., Suri M.: The solar radiation model for Open source GIS: implementation and applications. [in:] Proceedings of the Open source GIS - GRASS users conference 2002 - Trento, Italy, 11-13 September 2002 [on CD].

[9] Irish R.R.: Landsat 7 Automatic Cloud Cover Assessment. [in:] Proceedings of SPIE - The International Society for Optical Engineering 4049, August 2000, pp. 348-355.

[10] Irish R.R., Barker J.L., Goward S.N., Arvidson T.: Characterization of the Landsat-7 ETM+ Automated Cloud-Cover Assessment (ACCA) Algorithm. Photogrammetric Engineering and Remote Sensing, vol. 72(10), 2006, pp. 1179-1188.

[11] Kasten F., Czeplak G.: Solar and terrestrial radiation dependent on the amount and type of cloud. Solar Energy, vol. 24, 1980, pp. 177-198.

[12] Kryza M., Szymanowski M., Migała K., Pietras M.: Spatial information on total solar radiation: application and evaluation of the r.sun model for the Wedel Jarlsberg Land, Svalbard. Polish Polar Researches, vol. 31 (1), 2010, pp. 17-32.

[13] Miklánek P.: The estimation of energy income in grid points over the basin using simple digital elevation model. Annales Geophysicae, supplement II, vol. 11, 1993, pp. 296.

[14] NationalAeronauticsandSpaceAdministration, [on-line:]http://landsathandbook.gsfc.nasa.gov/pdfs/Landsat7_Handbook.pdf [access: 21.04.2016].

[15] Šúri M., Hofierka J.: A new GIS-based solar radiation model and its application to photovoltaic assessments. Transactions in GIS, vol. 8 (2), 2008, pp. 175-190.

[16] Š́ri M., Huld T.A., Dunlop E.D.: PV-GIS: a web based solar radiation database for the calculation of $P V$ potential in Europe. International Journal of Sustainable Energy, vol. 24, 2005, pp. 55-67.

[17] Šúri M., Huld T.A., Dunlop E.D., Albuisson M., Wald L.: Online data and tools for estimation of solar electricity in Africa: the PVGIS approach. [in:] The $21^{\text {st }}$ European Photovoltaic Solar Energy Conference; Proceedings of the International Conference; Dresden, Germany, 4-8 September 2006, WIP-Renewable Energies, pp. 2623-2626.

[18] Šúri M., Huld T.A., Dunlop E.D., Ossenbrink H.A.: Potential of solar electricity generation in the European Union member states and candidate countries. Solar Energy, vol. 81, 2007, pp. 1295-1305. 